\title{
MANUAL PARA CONSTRUIR UN ESTADO (LOS INFORMES DEL CONSEJO ASESOR PARA LA TRANSICIÓN NACIONAL DE CATALUÑA)
}

\author{
JOSU DE MIGUEL BÁRCENA \\ Profesor Titular (A) de Derecho Constitucional \\ Universidad Autónoma de Barcelona
}

SUMARIO

I. Introducción. II. Pars destruens: cómo separar a Cataluña del Estado español. III. Pars construens: la creación e institucionalización del Estado catalán. IV. La integración de Cataluña en la Unión Europea y en la sociedad internacional. V. Conclusiones.

\section{INTRODUCCIÓN}

El Consejo Asesor para la Transición Nacional (en adelante CATN), es un órgano administrativo creado por la Generalidad de Cataluña a través del Decreto 113/2013, de 12 de febrero, con el objetivo de dar apoyo al Gobierno autonómico en el asesoramiento de cuestiones relacionadas con la realización de una consulta para la independencia y la creación de lo que se han venido a denominar como «estructuras de Estado». Las funciones básicas, reconocidas en el artículo 2 del Decreto citado, tienen que ver con el análisis y las propuestas de actuación de las instituciones dependientes de la Generalidad, en aspectos jurídicos y políticos vinculados con la conversión de la Comunidad Autónoma de Cataluña en un Estado soberano. El CATN está compuesto por personas de reconocido prestigio en las diferentes disciplinas necesarias para llevar a cabo «el proceso» (art. 3.1) y está adscrito al Departamento de Presidencia, que le da soporte administrativo y logístico para la realización de sus tareas.

El número final de miembros del CATN ha sido de 15, el máximo que preveía la norma que lo fundaba (art. 3.2): 12 vocales, un presidente, una vicepresidenta y un secretario. Casi todos los integrantes del órgano consultivo se dedican a la docencia universitaria, excepto un empresario (Joan Font i Fabregó) y una 
periodista (Pilar Rahola) ${ }^{1}$. Desde su constitución el 13 de abril de 2013, hasta la publicación de los últimos trabajos, el CATN ha llevado a cabo 54 reuniones plenarias que han quedado plasmadas en más de 1300 páginas y 18 informes. El conjunto de los informes ha dado lugar a la publicación de un Libro Blanco a modo de síntesis, titulado La transición nacional de Cataluña, aparecido en septiembre de 2014 y editado por la Generalidad de Cataluña.

La base competencial para crear el CATN está en la autoorganización administrativa que establecen la Constitución, el Estatuto y las sucesivas normas autonómicas que se citan en el preámbulo del Decreto 113/2013: la Ley 13/1989, de organización, procedimiento y régimen jurídico de la administración de la Generalidad; la Ley 13/2008, de la presidencia de la Generalidad y el Gobierno, y; la Ley 26/2010, de régimen jurídico y procedimiento de las administraciones públicas de Cataluña. Sobre esta cuestión se generaron algunas dudas jurídicas, pues el partido político Ciudadanos recurrió al Tribunal Superior de Justicia de Cataluña (en adelante TSJC) el Decreto que creaba el CATN, entendiendo que ningún órgano de la Generalidad tenía competencia para llevar a cabo tareas que quedan fuera del alcance de la administración catalana, como sería el caso de la secesión.

El criterio clave para resolver la legalidad del Decreto en cuestión está probablemente en saber si se atribuyen funciones ejecutivas o no al CATN, en el sentido de que pudiera ser capaz de institucionalizar directamente alguna de las recomendaciones que hace a la propia administración de la que pende. No creemos que sea así, no solo por el tenor de la norma discutida, que otorga meras funciones de asesoramiento y análisis, sino porque la propia Generalidad, en el Decreto 16/2015, de 24 de febrero, nombró un Comisionado para la Transición Nacional, que en buena medida tenía como objetivo implementar las medidas necesarias para satisfacer muchas de las propuestas que el propio CATN había realizado en sus sucesivos informes. El nombramiento del Comisionado para la Transición Nacional de Cataluña recayó en Carles Viver Pi-Sunyer, que es también presidente del CATN. El Gobierno de la Nación planteó un conflicto positivo de competencia, invocando a su vez el artículo 161.2 CE, motivo por el cual la figura del Comisionado fue suspendida por el Tribunal Constitucional (en adelante TC) en providencia de 10 de julio de 2015.

El contenido del conjunto de los informes del CATN tiene dos partes más o menos diferenciadas. En la primera, que es a la que más atención se prestará, se analizan todas las cuestiones jurídicas relacionadas con la ruptura con el Estado español y la creación de un Estado propio. Para ello se abordan las distintas estrategias que pueden adoptarse para conseguir que Cataluña se independice (infor-

1 El resto de miembros del CATN son: Carles Viver Pi-Sunyer (Presidente), Núria Bosch (Vicepresidenta), Enoch Arbertí, Germà Bel, Carles Boix, Salvador Cardús, Ángel Castiñeira, Francina Esteve, Rafael Grasa, Josep María Reniu, Ferrán Requejo y Joan Vintró. 
mes n..$^{\circ}$, «La consulta sobre el futuro de Cataluña» y n. ${ }^{\circ} 4$, «Internacionalización de la consulta y del proceso de autodeterminación de Cataluña), las normas jurídicas que presidirán el proceso de transición nacional después de la ruptura constitucional con España (informe n. ${ }^{\circ} 10$, «El proceso constituyente») y el marco normativo y opciones políticas aplicables a la sucesión de Estados que se produciría en caso efectivo de secesión (informes $\mathrm{n} .{ }^{\circ} 7$, «La distribución de activos y pasivos» y n. ${ }^{\circ} 16$, «La sucesión de ordenamientos y Administraciones»).

En la segunda parte, el CATN lleva a cabo un estudio de diversos aspectos sociales, políticos y económicos, relacionados con la institucionalización del futuro Estado catalán. Por motivos de sobra comprendidos por el lector, de esta segunda parte solo nos interesarán los elementos prospectivos que tengan una verdadera naturaleza jurídica, como es el caso de la posible integración de Cataluña en la Unión Europea y en la sociedad internacional (informes n. ${ }^{\circ}$, «Las vías de integración de Cataluña en la UE» y n..$^{\circ} 13$, «La integración en la comunidad internacional»). El resto resulta de indudable interés, pero haría nuestro trabajo inabarcable y supondría un esfuerzo baldío, en la medida en que muchos de los temas que se abordan, dependen para su realización de una serie de variables que el CATN no está en condiciones de afirmar que puedan darse en un sentido o en otro, como es el caso de las relaciones de cooperación entre Cataluña y el Estado español (informe n. ${ }^{\circ}$ 3), la política monetaria (informe n. ${ }^{\circ}$ 8), las autoridades independientes (informe n. ${ }^{\circ} 12$ ), la seguridad social catalana (informe n. ${ }^{\circ} 15$ ) o la sociedad de la información (informe n. ${ }^{\circ} 5$ ).

\section{PARS DESTRUENS: CÓMO SEPARAR A CATALUÑA DEL ESTADO ESPAÑOL}

Si en el marco de la continuidad estatal, se presenta como un concepto discutible, por su carácter muchas veces fenomenológico, en el contexto de la aparición de un nuevo Estado, el poder constituyente adquiere una dimensión verdaderamente ontológica que hace que en su interior puedan distinguirse claramente dos fases ${ }^{2}$ : la pars destruens, donde se opera una destrucción o abolición del ordenamiento constitucional anterior, y la pars construens, momento de transición jurídica y política en el que se pasa a crear un ordenamiento constitucional de nuevo cuño que sustentará institucionalmente el Estado de reciente fundación. Sin duda, dentro de la panoplia de trabajos realizados por el CATN, el informe más importante es el n. ${ }^{\circ} 1$, titulado «La consulta sobre el futuro político de Cataluña», de 25 de julio de 2013. En él se identifican los pasos necesarios para desconectar a la Comunidad Autónoma de

2 Tomamos la distinción de García López, E.: «Poder constituyente evolutivo en la crisis de la modernidad política», en Yepes Arcila, H. y Suelt Cock, V. (Eds.): La Constitución, 20 años después. Visiones desde la teoría y la práctica constitucional, Ibáñez, Bogotá, 2012, pp. 357-417.

UNED. Teoría y Realidad Constitucional, núm. 37, 2016, pp. 499-527 
España, se analizan las vías constitucionales para la realización de un referéndum y se ofrecen argumentos legitimadores por los cuales Cataluña tendría derecho a la autodeterminación para crear un Estado propio.

\section{Por qué debe realizarse una consulta independentista en Cataluña: demoscopia, historia y democracia}

$\mathrm{El}$ informe n. 1 comienza justificando por qué en Cataluña debe realizarse una consulta sobre la independencia. Recurriendo al criterio estadístico, en primer lugar se realiza una media aritmética de las encuestas que en los distintos medios de comunicación mostraban el porcentaje de población favorable a la misma. El periodo apenas abarca un año y se salda con un resultado ampliamente favorable (entre un 68,9 y un $83,9 \%$ de los encuestados). En segundo lugar, se utilizan los resultados electorales de las elecciones noviembre de 2012 a modo de radiografía para saber qué porcentaje de votantes apoyaban el referéndum, teniendo en cuenta la posición que los distintos partidos tenían sobre la cuestión. Con el PSC actuando de bisagra, dada la ambigüedad que ha mostrado sobre el tema, el CATN llega en todos los casos a la conclusión de que hay un respaldo amplio de votantes a la consulta (entre el 59,55 y el 73,99\%). Por lo tanto, el órgano asesor de la Generalidad podría haber justificado la necesidad del referéndum sobre la independencia en los resultados electorales y en el apoyo claro de los ciudadanos mostrado en las encuestas. Sin embargo, va más allá y construye una serie de argumentos legitimadores que operan de manera amontonada, nunca subsidiaria, dependiendo de las circunstancias y actores a los que se tenga que hacer frente el «proceso» independentista.

De esta manera, el informe n. ${ }^{\circ} 1$ comienza hablando de la «legitimidad histórica» para celebrar la consulta, consecuencia lógica de la lucha permanente de Cataluña por su soberanía y autogobierno (p. 33). Esta es probablemente una de las partes más polémicas del informe, pues parece anclarse en el modelo histórico romántico que predomina en la opinión pública catalana desde que en el año 2012 comenzarán las movilizaciones por la independencia. Se señala, de esta forma, que desde el año 987 se va desarrollando la «nación catalana, con rasgos culturales y lingüísticos comunes y vínculos de solidaridad», así como un Estado, afianzado a través de la expansión por el Mediterráneo de los siglos XIII y XIV. El CATN elude en todo momento señalar que Cataluña perteneció a la Corona aragonesa y española, afirmando que con la finalización de la Guerra de Sucesión en 1714 , se corta un «largo proceso de consolidación nacional y estatal», basado en instituciones constitucionales y protoliberales propias (p. 35$)^{3}$.

3 Una visión distinta sobre la cuestión, en Canal, J.: Historia mínima de Cataluña, El Colegio de México - Turner, México - Madrid, 2015. 
El informe analizado continúa haciendo repaso de los distintos principios que pueden avalar la realización de una consulta independentista en Cataluña. Se habla de los principios representativo, liberal y de igualdad, se alude al federalismo plurinacional, que se encontraría inserto en el dictamen del Tribunal Supremo (en adelante TS) de Canadá sobre Quebec, e incluso se señala que el referéndum responde a una concepción avanzada y cosmopolita de la democracia. Lo importante es señalar que el CATN no pretende en ningún momento construir un relato legitimador coherente sobre la cuestión, sino que va acumulando argumentos que pueden ser utilizadas indistintamente en diversos escenarios y por diversos actores. Es por ello que al final se diga que más allá de los argumentos normativos, «la consulta es funcional, permite salir del callejón sin salida político actual» (p. 45) y que en ningún momento se presenten dudas jurídicas o filosóficas que puedan poner en cuestión, de manera razonada, ninguno de los principios o justificaciones que se van desgranando en la segunda parte del informe. De esta forma, se pasa en seguida a las «estrategias jurídicas para la convocatoria de una consulta legal de acuerdo con el derecho interno» (p. 48).

\section{Las vías legales para la realización de un referéndum independentista}

Sobre esta cuestión, el CATN hace suyas las indicaciones del informe que previamente había realizado el Instituto de Estudios Autonómicos, donde se identificaban las cinco vías legales para llevar a cabo la consulta. Para el CATN, «el objetivo primero y fundamental de la Generalitat debería ser conseguir que efectivamente pudiera convocarse una consulta y, subsidiariamente, si eso no fuera posible, que quedara patente, de la forma más clara posible, que es el Estado quien se niega a permitirla y que lo hace por motivos políticos, no jurídicos» (p. 49, informe n. ${ }^{\circ}$ ). La consecución de un mecanismo legal para llevar a cabo el referéndum debe realizarse en el menor tiempo posible, para que «los ciudadanos de Catalunya no tengan la sensación de una pérdida de tiempo innecesaria» (p. 49), eligiendo la fórmula que garantice el máximo protagonismo de la Generalidad, con el objetivo de asegurar una mayor libertad a la hora de convocarla y una mayor incidencia en la fijación de los elementos configuradores de la consulta.

La primera vía es la del artículo 92 CE. Según el CATN, dicho artículo y la Ley Orgánica Reguladora de las Distintas Modalidades de Referéndum (LORMR), serían aval suficiente para celebrar una consulta en Cataluña convocada y celebrada por el Estado. Si, a pesar de los señalado por la doctrina ${ }^{4}$, no se pudieran

4 Por ejemplo, Carreras Serra, F.: «¿Puede celebrarse un referéndum en Cataluña?», El Cronista del Estado Social y Democrático de Derecho, n. ${ }^{\circ} 239,2014$. Es necesario distinguir esta posición, de otras, también favorables a realizar una consulta, pero que no devienen necesariamente del artículo $92 \mathrm{CE}$, como por ejemplo, Rubio Llorente, F.: «Un referéndum para Cataluña», El país, 8 de octubre de 2012; Ruiz SoroA, J.M.:

UNED. Teoría y Realidad Constitucional, núm. 37, 2016, pp. 499-527 
realizar consultas de dimensión autonómica, habría que reformar la LORMR y de paso dar un mayor protagonismo a la Generalidad en cuestiones laterales a la convocatoria, que nunca podrían afectar a la facultad de la autorización, reservada para el Estado según el artículo 149.1.32 CE (p. 52). Si la fórmula del artículo 92 CE no funciona, porque al fin y al cabo implica una decisión política del Gobierno central y de las Cortes Generales, el CATN propone la delegación o transferencia de la competencia estatal para convocar una consulta, procedimiento que «con todas las diferencias», es «el empleado por el Reino Unido en el caso del referéndum escocés y disfruta por lo tanto de la «homologación» internacional derivada de este ilustre precedente en términos democráticos» (p. 53). Como se sabe, las Cortes generales rechazaron esta vía en abril de 2014, después de la proposición de ley orgánica realizada por el Parlamento de Cataluña.

En la medida en que el CATN considera que lo ideal es el protagonismo central de la Generalidad en la realización de la consulta, abre por tanto las vías jurídicas autonómicas. La primera sugerencia es la de utilizar la Ley 4/2010, de consultas populares por vía de referéndum, que impugnó el Estado ante el TC, en la medida en que podría estar vulnerando la doctrina sobre la materia establecida por el propio TC en la Sentencia 103/2008. Como la Ley en cuestión está parcialmente suspendida y en espera a la decisión del Alto Tribunal, el CATN considera que es mejor llevar a cabo una ley específica para la consulta independentista, que podría tener éxito solo si el Estado aceptara que «los criterios utilizados para caracterizar las consultas populares y diferenciarlas de los referéndums $[\ldots]$ son suficientemente significativos para aceptar que no se trata de referéndums encubiertos». Efectivamente, este fue el camino que finalmente siguieron los impulsores del proceso independentista, a través de la aprobación de la Ley del Parlamento de Cataluña 10/2014, de consultas populares no referendarias y otras formas de participación ciudadana, norma que fue parcialmente anulada por la STC 31/2015, precisamente, por haber sido incapaz de construir conceptualmente una distinción jurídicamente relevante entre consulta no referendaria y referéndum.

Por último, el CATN recomienda que si todas las vías anteriores fallan, la Generalidad inste a las Cortes Generales a realizar una reforma constitucional. Dependiendo del contenido de la misma, el mecanismo a utilizar será distinto: si solo se pretende permitir que las Comunidades Autónomas realicen referéndums, convocándolos y autorizándolos, bastará con utilizar el artículo 167 CE (reforma simple) para modificar los artículos 92 y 149.1.32 CE. Si lo que se quiere es permitir que las Comunidades Autónomas realicen referéndums sobre asuntos que después requerirían a su vez la reforma constitucional (por ejemplo, la secesión),

«¿Es posible regular la secesión aquí y ahora?», en VV.AA.: La secesión de España. Bases para un debate desde el País Vasco, Tecnos, Madrid, 2014, pp. 19-36 o Aguado Renedo, C.: «Sobre un eventual referéndum consultivo catalán en el proceso soberanista», Cuadernos de Alzate. Revista Vasca de la Cultura y las Ideas, n. ${ }^{\circ}$ 46/47, 2013 , pp. 27-48. 
se tendría que utilizar el artículo 168 CE (reforma agravada). Parecería que con esta diferenciación, el CATN estuviera aceptando la tesis que señala que aun siendo consultivo, un referéndum independentista no sería una decisión sobre soberanía, sino de soberanía ${ }^{5}$. En cualquier caso, esta petición de reforma constitucional (art. 87.2 CE), no se ha llevado a cabo hasta el momento.

\section{La consulta en el marco del derecho de la Unión Europea y el derecho internacional}

El siguiente paso del CATN es identificar en el derecho de la Unión Europea (UE) y en el derecho internacional, aquellas normas y principios que reforzarían, al menos políticamente, la realización de una consulta soberanista en Cataluña.

En lo que respecta al principio democrático, el informe n. ${ }^{\circ} 1$, que continuamos analizando, señala que especialmente el Tratado de la UE (en adelante TUE), contiene numerosas disposiciones (arts. 2 y 11 TUE) que obligarían al Estado español a permitir un referéndum en Cataluña, en la medida en que avalarían «el derecho de los ciudadanos a participar en las decisiones políticas que les afecten» (p. 62). Con respecto al derecho de autodeterminación, el CATN señala que «podría hacerse una interpretación evolutiva de la excepción del principio de no injerencia recogido en la Resolución 2625 de la Asamblea General de Naciones Unidas, en los supuestos de los pueblos oprimidos dentro de un Estado democrático y desarrollado». Es decir, que podría «sostenerse que un pueblo que pretenda ejercer un derecho de autodeterminación externo (derecho de secesión) mediante este supuesto, puede hacerlo si demuestra fehacientemente a la Comunidad internacional que persigue una causa legítima, si logra convencer al máximo número posible de Estados de la existencia de injusticias concretas y sustanciales y, por último, si muestra claramente que ha utilizado, sin éxito, todos los medios a su alcance para intentar resolver previamente los conflictos con el Estado matriz» (p. 63). Este párrafo es clave, como se verá después, y su importancia reside en que es un planteamiento completamente autónomo del CATN (pese a la interesada alusión al dictamen del TS de Canadá sobre Quebec) sobre el derecho de autodeterminación de un pueblo que es discriminado y políticamente agraviado por el Estado donde se encaja. Como se verá después, esta tesis permitirá llevar hasta el final la posibilidad de encontrar una legitimidad sobrevenida para que Cataluña realice una declaración unilateral de independencia (en adelante DUI).

Sea como fuere, el propio órgano consultivo reconoce que los derechos y principios arriba citados, así como el principio de protección de las minorías, no son justiciables ni en el ámbito internacional ni en el de la UE. Ni los ciudadanos

5 Esta distinción, en SOLOZÁBAL, J.J.: «La autodeterminación y el lenguaje de los derechos», Cuadernos de Alzate. Revista Vasca de la Cultura y las Ideas, n. ${ }^{\circ}$ 46/47, 2013, pp. 216-231. 
ni la Generalidad podrían reclamar directamente a ningún órgano de la UE, el Consejo de Europa o los órganos judiciales internacionales, su vulneración por parte del Estado español. Como posibilidades indirectas, el CATN señala una improbable activación del artículo 7 TUE, que permite sancionar a un Estado miembro de la UE por violación grave de alguno de los valores o derechos del ordenamiento comunitario, y el uso de las vías no jurisdiccionales previstas por los Protocolos Facultativos del Pacto Internacional de Derechos Civiles y Políticos y del Pacto Internacional de Derechos Económicos, Sociales y Culturales.

El CATN reconoce, no obstante, que el principio democrático, el derecho de autodeterminación y el principio de protección de las minorías están integrados en el sistema constitucional español, en la medida en que forman parte de Tratados firmados y ratificados por el Estado. Por ello, como consecuencia de la cláusula hermenéutica del artículo 10.2 CE, los poderes públicos estatales tendrían la obligación de interpretar las normas de la Constitución relacionadas con la participación política y los referéndums (arts. 23 y $92 \mathrm{CE}$ ) en favor de las aspiraciones de la sociedad catalana para que se realice una consulta popular sobre la independencia. Este argumento no tiene en cuenta la doctrina consolidada a nivel teórico y jurisprudencial, que señala que el catálogo de derechos fundamentales de la Constitución española es cerrado, por lo que la vía interpretativa no puede servir para incorporar un derecho — el de autodeterminación — que fue rechazado expresamente por el propio poder constituyente ${ }^{6}$.

\section{La implementación de los resultados de una consulta legal}

El informe n. ${ }^{\circ} 1$ dedica un buen número de páginas a abordar aspectos «técnicos» de la consulta (claridad de la pregunta, fecha, censo, quórum y mayorías y administración electoral). Son aspectos clave desde el punto de vista del proceso democrático, pero no son importantes desde la perspectiva que ha adoptado este trabajo, que es la del poder constituyente que va tomando decisiones para crear un Estado. Sí interesa, por el contrario, las propuestas que hace el CATN para implementar las diferentes respuestas que se pueden obtener en un referéndum independentista, respuestas que lógicamente dependen de lo que se haya preguntado previamente a través del modelo de consulta elegido por los poderes públicos catalanes.

En caso de que ganara el «no», la Generalidad no podría plantear ninguna iniciativa política o jurídica destinada a conseguir la independencia de Cataluña. Ello no impediría, en todo caso, que se volviera a plantear otra consulta sobre el tema, por ejemplo cada 15 años, como ocurrió en Quebec entre el primer y se-

6 Como recuerda Tajadura, J.: «El derecho de autodeterminación», García Herrera, M.Á., Vidal Beltrán, J.M. y Sevilla, J. (Coords.): El estado autonómico: integración, solidaridad, diversidad, Colex, Ministerio de Administración Pública e INAP, Madrid, 2005, Vol. 2, pp. 177-206. 
gundo referéndum (1980 y 1995). Además, se podrían presentar otro tipo de reformas constitucionales distintas a las derivadas de una posible independencia, dependiendo de los programas de los partidos (p. 126). En el caso de que se hiciera una pregunta múltiple (como finalmente ocurrió en el referéndum «informal» del 9 de noviembre), los resultados pueden ser difícilmente interpretables, a menos que se produzca una mayoría absoluta a favor de alguna de las opciones. Si la pregunta se refiriese a la creación de un «estado propio» y en esta locución se consideraran incluidas fórmulas federales o confederales, la implementación del «sí» exigiría una reforma de la Constitución, muy probablemente por la vía agravada de reforma y, por lo tanto, con un nuevo referéndum en el que los ciudadanos podrían volver a votar (p. 134)

En el caso de que el resultado de la consulta sea favorable a la independencia, incluso aunque el «sí» vaya acompañado de una cláusula de salvaguardia de la legalidad española, el CATN señala el siguiente camino: para empezar, aunque el referéndum tenga carácter consultivo, resulta innegable que el mismo produce obligaciones jurídicas en relación a los poderes públicos, que deberían actuar en correspondencia. Es decir, se parte de la tesis de que el artículo $92 \mathrm{CE}$ es materialmente decisorio. A partir de ahí, la Generalidad puede presentar una iniciativa de reforma constitucional (arts. 166 y $87.2 \mathrm{CE}$ ) o bien plantear una negociación directa con el Estado, «al considerar que se está de hecho ante un momento constituyente nuevo» (p. 122). Si el Estado, bien mediante una decisión política, bien mediante un rechazo de las Cortes Generales a abordar la reforma constitucional, bloqueara la posibilidad de implementar el resultado favorable a la independencia en la consulta, se utilizarían otros «procedimientos legales» al margen de los previstos en la actualidad (p. 122).

Efectivamente, en caso de que el proceso político institucionalizado fracase, el CATN plantea la posibilidad de un proceso constituyente para Cataluña, que según su opinión no sería ilegal o contra legem sino «alegal» o extra legem. Partiendo de esta peculiar — por llamarla de alguna manera - interpretación, el órgano de consulta plantea el mismo escenario que el anteriormente esbozado: propuesta de reforma constitucional para hacer efectiva la secesión o negociación política directa de la Generalidad con el Gobierno central. Si la independencia queda bloqueada, el CATN propone trasladarse desde el derecho a la política («el problema que se plantea es de naturaleza esencialmente política y no jurídica») y recurrir a la mediación internacional para resolver el conflicto, «sin excluir como última solución vías unilaterales como la DUI» (declaración unilateral de independencia) (p. 124).

7 En el referéndum informal (e ilegal) del 9 de noviembre de 2014, los votantes se enfrentaron a una doble pregunta eliminatoria: «QQuiere que Cataluña sea un Estado?» y «En caso afirmativo, ¿quiere que Cataluña sea un Estado independiente?». Con esta complejidad se pretendía satisfacer las distintas sensibilidades de los partidos políticos y movimientos sociales que eran favorables al derecho a decidir, pero no siempre eran favorables a la independencia. 


\section{Qué hacer si no se puede realizar la consulta independentista}

La negativa del «Estado a convocar una consulta, a autorizarla o a permitir que se realice, abriría a la Generalitat la posibilidad de emplear, legítimamente desde una perspectiva política, vías alternativas de convocatoria de consultas, a través de consultas no oficiales o elecciones plebiscitarias, que podrían ser implementadas mediante declaraciones unilaterales del Parlamento de Cataluña» (p. 135). En cuanto a la primera cuestión, el CATN distingue entre la posibilidad de realizar un referéndum «aplicando la legalidad catalana a pesar de su suspensión» o la organización de una consulta que «correspondiera exclusivamente a entidades de la sociedad civil, si bien contando con el respaldo indirecto de la Generalitat y de los ayuntamientos». Como ya se sabe, finalmente la Generalidad y las asociaciones privadas que promueven la independencia en Cataluña, optaron por este segundo camino, realizando una consulta del 9 de noviembre de 2014, a pesar de que el TC la suspendió días antes después del recurso presentado por el Gobierno central. El CATN ya advertía que la utilización exclusiva de la legalidad catalana podría llevar a la «confrontación total con el Estado», mientras que la realización de una consulta sin garantías electorales podría conducir a una «fácil conducta de desprestigio» desde los actores e instituciones contrarias a la misma (p. 135).

Como segunda gran alternativa, el órgano asesor presenta la posibilidad de realizar unas elecciones plebiscitarias, que también habían sido aludidas en el informe del Instituto de Estudios Autonómicos en marzo de 2013 sobre la realización de una consulta independentista en Cataluña. El CATN no entra a valorar el desprestigio histórico que en Europa tiene el adjetivo plebiscitario, señalando que unas elecciones de este tipo ayudarían a conocer directamente la posición de los ciudadanos sobre la secesión desde una perspectiva legal, eficaz y democrática. Tampoco se analiza cómo deberían contarse los resultados de unas elecciones meramente autonómicas donde los distintos partidos políticos que concurren a las urnas pueden eludir el carácter plebiscitario de las mismas. Este problema se ha planteado en las elecciones al Parlamento de Cataluña de 27 de septiembre de 2015, que siguiendo las recomendaciones del CATN, fueron políticamente transformadas en unas elecciones plebiscitarias por el Gobierno de la Generalidad, dándose una mayoría de escaños favorables a las formaciones independentistas, y una mayoría de votos de partidos que no se pronunciaron durante la campaña electoral a favor de la secesión.

\section{La legitimidad internacional de una declaración unilateral de} independencia

Una vez realizado el referéndum informal o las elecciones plebiscitarias, el CATN analiza el contexto institucional propicio para que el proceso de autode- 
terminación nacional de Cataluña sea un éxito. La prioridad para el órgano consultivo es la comunidad internacional, motivo por el cual realiza el informe n. ${ }^{\circ} 4$, presentado el 20 de diciembre de 2013, titulado «Internacionalización de la consulta y del proceso de autodeterminación de Cataluña». Para seguir el hilo de la argumentación, hemos preferido privilegiar los aspectos relacionados con el papel de las organizaciones y actores institucionales en lo referido al reconocimiento de Estados creados a partir de la secesión. En todo caso, el CATN ofrece una panoplia de recomendaciones muy amplias, para que «el Gobierno de Catalunya module su discurso de justificación del proceso de autodeterminación en función de las audiencias a las que se dirija en cada momento» (p. 6).

Para conseguir la aquiescencia de Estados y organizaciones internacionales, el CATN aconseja seguir por el camino ya expresado en las páginas anteriores, es decir, construir una legitimación de la consulta y la secesión haciendo hincapié en que éstas son el remedio necesario para que Cataluña recupere la dignidad institucional, en la medida en que vive en un Estado que siempre rechaza cualquier intento de incrementar el autogobierno, reconoce un tipo muy limitado de autonomía administrativa y con escasas garantías constitucionales (p. 9). Esta justificación evita según el CATN tener que recurrir a construcciones históricas alambicadas y permite además presentar a Cataluña como un sujeto agraviado desde la perspectiva cultural y lingüística. Porque si «bien es cierto que Catalunya sufre unos desequilibrios fiscales gravísimos, este caso no tiene nada que ver con el de la región de la Padania y, por lo tanto, cualquier identificación de los dos casos sería, en primer lugar errónea y, en segundo lugar, muy nociva para la causa catalana a nivel internacional» (p. 11).

A pesar de que el derecho natural («derecho inalienable de una comunidad nacional») y la filosofía moral («autonomía de los individuos para construir un Estado independiente»), son elementos presentes en la sociedad internacional, y pueden operar como elementos normativos subalternos, la opción que según el CATN debe seguir la Generalidad para conseguir apoyos fuera de España, es «la autodeterminación como último recurso para poner remedio a una situación injusta». La situación injusta sería la mala calidad del sistema de descentralización política del Estado español, para la que se ofrecen abundantes (y discutibles) argumentos (pp. 19-24). Para el órgano asesor, las condiciones que permitirían a Cataluña ejercer el derecho de autodeterminación (p. 24) como último recurso no se encuentran plenamente consensuadas entre los propios partidarios de esta justificación de la secesión, a pesar de lo cual realiza un listado: la violación sistemática de los derechos humanos, una ocupación militar injusta y «la violación de los acuerdos de concesión de autonomía por parte del Estado central y la imposibilidad de articular un sistema alternativo federativo o de soberanías compartidas» (p. 24).

Este último supuesto es de la propia cosecha del CATN. No hay prácticamente ningún autor en el derecho internacional y comparado que defienda el $d e$ recho de secesión, como remedio para poner fin a una injusticia, fuera de la violación 
sistemática de derechos humanos o una ocupación militar extranjera ${ }^{8}$. En el informe $n .{ }^{\circ} 1$, cuando se habla de los principios jurídicos internacionales que avalarían la consulta, se afirma también, sin ninguna referencia doctrinal que lo avale, «que hoy está arraigando la tesis de que, en virtud sobre todo del principio democrático, toda comunidad política que tenga una población, un territorio y un poder público propio que se ejerza efectivamente sobre esa población y en ese territorio, si manifiesta su voluntad de autodeterminarse, incluida la voluntad de secesión, siempre que lo haga democrática y pacíficamente y respetando los derechos de los ciudadanos y especialmente los de las minorías, puede hacerlo sin que ello suponga cometer una infracción internacional y, en consecuencia, sin que la invocación del principio de integridad territorial del Estado matriz $[\ldots .$.$] ni la$ supremacía de la Constitución, puedan servir como argumentos para tachar de ilícitos internacionales las declaraciones unilaterales de independencia» (p. 70, informe n. ${ }^{\circ} 1$ ).

Esta larga cita trae causa de la opinión consultiva emitida por el Corte Internacional de Justicia (en adelante CIJ), el 22 de julio de 2010, sobre la conformidad con el derecho internacional de la declaración unilateral de independencia de Kosovo. Ciertamente, extraña el peso que tiene en los argumentos del CATN dicha opinión a lo largo de varios informes (n. ${ }^{\circ} 4,10$ y 13), por dos razones fundamentales. La primera, porque si el órgano consultivo catalán está teorizando una variante de la secesión como remedio para lograr la legitimidad internacional desde la perspectiva de lo que es un auténtico derecho, lo cierto es que la opinión citada de la CIJ se niega a valorar si Kosovo tenía derecho a la autodeterminación externa, en cuanto remedial secession, a pesar de que parece que concurrían las circunstancias requeridas para aplicar la cláusula de excepción de los límites de la autodeterminación nacional en relación con el principio de integridad territorial de los Estados. La segunda, porque no puede generalizarse la tesis de que a partir del dictamen de la CIJ sobre Kosovo, en el derecho internacional las DUI u otros cambios de estatus territoriales son siempre legales, cuando se hagan de forma pacífica y democrática9. Por ejemplo, la Resolución 68/262 aprobada por la

8 Allen Buchanan, en el prólogo a la edición española de su estudio clásico, cuando aborda la cuestión catalana, parece inclinarse hacia esa posibilidad; Buchanan, A: Secesión. Causas y consecuencias del divorcio político, Ariel, Barcelona, 2013. Sin embargo, en el grueso de la obra citada, y en su otra obra monográfica sobre el tema, Justice, Legitimacy, and Self-Determination: Moral Foundations for International Law, Oxford University Press, Oxford, 2004, las demandas de más autonomía no son planteadas como un argumento moral a favor de la secesión, sino como una distinción conceptual necesaria para comenzar a trabajar sobre el objeto de estudio.

9 El CATN lo suscribe de la siguiente manera en la p. 140 del informe n. ${ }^{\circ} 1:$ «En definitiva, las DUI no son contrarias al derecho internacional si son el resultado de un procedimiento democrático llevado a cabo en un contexto pacífico, es decir, sin intervención de la fuerza o la violencia. Ciertamente, el contexto político de Kosovo político e institucional (intervención de Naciones Unidas) que permitió la DUI de Kosovo no es comparable al de la Catalunya actual, pero los principios derivados de la Resolución de la Corte Internacional de Justicia tienen una potencialidad que va más allá del caso concreto en el marco en el que surgieron» (las cursivas son nuestras). 
Asamblea General de la ONU, el 27 de marzo de 2014, insta a los Estados, organizaciones internacionales y órganos especializados a no reconocer los cambios en el estatuto de Crimea y Sebastopol como consecuencia del carácter ilícito del referéndum que precedió su anexión a Rusia ${ }^{10}$.

\section{La declaración unilateral de independencia desde la perspectiva del derecho interno}

Para el CATN, la DUI del Parlamento de Cataluña tiene un carácter instrumental como culminación de la vía alternativa abierta mediante la celebración de unas elecciones plebiscitarias cuyo resultado fuera mayoritariamente favorable a las fuerzas políticas partidarias de la independencia de Cataluña (p. 138, seguimos con el informe n. ${ }^{\circ}$ ). Una vez dicho esto, el órgano asesor entra a valorar cuál sería la vía procesal a seguir, dentro del esquema de normas parlamentarias y estatutarias, para llevar a cabo la DUI. Según el CATN, ésta «no tiene que ser demasiado larga en su parte dispositiva, puesto que básicamente se tiene que limitar a reflejar la voluntad de constituir Catalunya como Estado independiente» (p. 138). Podría realizarse mediante una resolución parlamentaria, pero dada la trascendencia del acto, el CATN recomienda una proposición de ley presentada por todos los grupos parlamentarios favorables, utilizándose la vía de urgencia para que se aprobase en menos de una semana ${ }^{11}$. Por lo demás, en la medida en que la DUI es una norma no prevista reglamentariamente, la Mesa del Parlamento debería fijar previamente el tipo de mayoría necesaria para sacar adelante la iniciativa.

Para el CATN, una DUI no se ajustaría a las disposiciones del ordenamiento jurídico español, porque Cataluña no está reconocido como sujeto soberano en el mismo. Por ello, el Estado podría recurrir en hipótesis a dos mecanismos inmediatos para neutralizarla: el artículo 161.2 CE, que alude a la suspensión automática de las disposiciones y resoluciones autonómicas impugnadas por el

10 En circunstancias distintas, el Consejo de Seguridad, en la Resolución 1808 (2008), de 15 de abril, reafirmó el compromiso de todos los «Estados miembros con la soberanía, la independencia y la integridad territorial de Georgia», con respecto a las DUI de Osetia del Sur y Abjasia realizadas a principios de la década de 1990 .

11 Ver en este sentido la Resolución 1/XI del Parlamento de Cataluña, sobre el inicio del proceso político en Cataluña como consecuencia de los resultados electorales del 27 de septiembre de 2015, aprobada el 9 de noviembre de 2015. En la misma, el Parlamento catalán, «como depositario de la soberanía y como expresión del poder constituyente», constata que el mandato democrático obtenido en las pasadas elecciones del 27 de septiembre de 2015 se basa en una mayoría en escaños de las fuerzas parlamentarias que tienen como objetivo que Cataluña sea un Estado independiente, declara el inicio del proceso de creación de un Estado catalán independiente en forma de república, proclama la apertura de un proceso constituyente para preparar las bases de la futura constitución catalana e insta al futuro gobierno a adoptar las medidas necesarias para hacer efectivas estas declaraciones. La Resolución 1/XI ha sido anulada por el TC, mediante la sentencia 259/2015, de 2 de diciembre. 
Gobierno central y, el artículo 155 CE, referido a la coerción federal dentro del Estado autonómico. Más allá de estas actuaciones, el Estado podría utilizar los estados de excepción y de sitio, regulados en la LO 4/1981. En cuanto al primero de los supuestos, el CATN señala que «es discutible, aunque no impensable, que una DUI pudiera constituir un supuesto de hecho que justificara la declaración de un estado de excepción, a no ser que se forzara la interpretación de los efectos que conlleva una DUI considerando que se estaba alterando gravemente el normal funcionamiento de las instituciones democráticas». En cuanto al segundo, el estado de sitio, su aplicación se fundamentaría también en una interpretación amplia y forzada del contenido del precepto regulador, «ya que una DUI no constituye ni una insurrección ni un acto de fuerza, sino que se trata de una actuación vinculada de forma estrecha al principio democrático» (p. 154).

Para el CATN, una DUI tampoco tendría consecuencias penales para sus impulsores. Así, el delito de rebelión, previsto en el artículo 472.5 CP, no sería de aplicación si la actuación de las instituciones de la Generalidad no fuera acompañada de ningún tipo de violencia, aunque en este caso la definición de lo que es violentar el ordenamiento jurídico es bastante elástica. El delito de sedición (art. $544 \mathrm{CP}$ ) también sería de difícil aplicación, ya que «si bien por una parte la implementación de una declaración unilateral a favor de un régimen de autogobierno caracterizado por una nota de soberanía podría conllevar la inaplicación de leyes o podría también suponer el incumplimiento de determinados acuerdos o de resoluciones administrativas o judiciales, no parece, en cambio, que estuviera presente - al menos de forma necesaria - el requisito de proceder tumultuariamente, si entendemos por tumulto la confusión, el alboroto o revuelo precedido por una multitud» (cursivas en el original) (p. 154).

\section{PARS CONSTRUENS: LA CREACIÓN E INSTITUCIONALIZACIÓN DEL ESTADO CATALÁN}

La DUI no supone la desconexión inmediata con el Estado español, sino la manifestación de la voluntad de órgano autoproclamado como soberano (el Parlamento de Cataluña), en el sentido de construir un Estado propio. A partir de ese momento comienza, según el CATN, el proceso para crear el Estado catalán, que como se verá precede a su institucionalización en la medida en que la elaboración de la Constitución se difiere a un acto constituyente posterior. Una vez se ha creado el Estado, el Parlamento de Cataluña deberá proclamar la independencia, que es simplemente el reconocimiento a posteriori de la existencia efectiva de esa realidad estatal. El CATN explica y detalla los pasos a seguir después de la DUI, en el informe n. ${ }^{\circ} 10$, publicado el 14 de julio de 2014, y titulado genéricamente «El proceso constituyente». 


\section{Actores, estrategias y escenarios para fundar el nuevo Estado catalán}

Como ya hemos señalado, una vez realizada la consulta o celebradas las elecciones plebiscitarias donde el resultado fuera favorable a la independencia, el Parlamento regional estaría según el CATN legitimado para realizar la DUI que contuviera, entre otros elementos, el ofrecimiento - requerimiento al Estado para negociar la forma en la que se acordaría la salida de Cataluña de España. En principio se prevé el escenario de la colaboración leal del Gobierno central, respetuoso con la voluntad democráticamente expresada de los catalanes, que además debería de aceptar la mediación de organizaciones internacionales, otros Estados o personalidades. En este periodo inmediatamente posterior a la DUI, la Generalidad tendría que buscar el reconocimiento internacional, negociar las condiciones de la incorporación Cataluña a la UE y preparar internamente la creación del nuevo Estado. Para que el proceso sea un éxito, el CATN considera decisiva la movilización ciudadana y la participación activa de la sociedad civil favorable a la secesión, siendo necesario asimismo que se tenga en cuenta las opiniones e intereses de las «minorías discrepantes», a las que no se llega a caracterizar como minoría nacional española (p. 10, informe n. ${ }^{\circ} 10$ ).

En esta fase de transición, donde lo viejo muere y lo nuevo nace, de acuerdo a la filosofía gramsciana, la capacidad de actuación de la Generalidad irá lógicamente más allá de las competencias que le reconoce el bloque de constitucionalidad español, especialmente en relación con la creación y la puesta en funcionamiento de las «estructuras estatales» del nuevo Estado independiente. Según el CATN, las estructuras básicas que han de crearse en este periodo son las relativas a la hacienda y la administración económica y tributaria, la seguridad social, el poder judicial, la seguridad pública, las infraestructuras, las telecomunicaciones, la energía y el agua, y las relaciones exteriores. Todas estas decisiones tendrían que ser provisionales y no prejuzgar, en la medida de lo posible, las decisiones que al respecto tome la futura Constitución catalana (p. 12). Además, deberían de adoptarse lo antes posible, para no crear inseguridad jurídica, siendo deseable que se firmara un protocolo de actuación en forma de acuerdo político público, del que podría formar parte el Estado español o no.

En todo caso, según el CATN, también es posible un escenario de no-colaboración del Estado durante esta fase intermedia. En este caso «se produciría una situación de bloqueo político, con una carga potencial de conflicto institucional muy elevada» (p. 13), en la que la actitud del Gobierno central puede tener grados de intensidad diversos: desde una posición pasiva, no beligerante respecto de los actos que se vayan tomando desde Cataluña para avanzar el proceso, hasta una posición activa en la que se hagan uso de los diversos instrumentos jurídicos previstos para situaciones de emergencia constitucional. Según el CATN, la oposición del Estado estaría sometida a los límites previstos por el ordenamiento jurídico español para estas situaciones, siendo imposible la suspensión de los derechos y libertades de las personas, más allá de lo previsto en el artículo $55 \mathrm{CE}$. Por 
lo demás, existiría en última instancia la garantía del artículo 7 TUE, que sirve para que la UE reaccione frente a situaciones donde los Estados miembros violen los valores y principios fundamentales de los Tratados comunitarios (p. 14).

La Generalidad, ante el bloqueo político, debería recurrir a la mediación internacional para convencer al Estado español. Si no lo consigue, para «hacer efectiva la voluntad popular expresada a favor de la creación de un Estado independiente», la alternativa sería proclamar unilateralmente la independencia, que constituye la expresión de la «voluntad de desconectar de manera inmediata de las instituciones del Estado español y de ordenamiento jurídico, de tal manera que ya no se reconoce la autoridad de las primeras ni la vinculación al segundo» (p. 15) ${ }^{12}$. La proclamación del Estado catalán no significa, según el CATN, que los órganos de la Generalidad tengan un control efectivo sobre la población y el territorio de Cataluña. Conviene, en este sentido, leer con atención el siguiente párrafo del informe que venimos analizando, teniendo en cuenta la situación política e institucional que podría vivirse en un contexto de búsqueda de efectividad estatal por parte de las instituciones autonómicas (las comillas son nuestras): «Es posible que, al menos durante un tiempo, se produzca un conflicto entre los dos órdenes, de manera que las autoridades y los ordenamientos de cada uno de ellos pugnen por imponerse y obtener el control» (p. 16).

\section{La Constitución provisional de Cataluña}

En cualquiera de los escenarios indicados, se produciría en todo caso una desvinculación formal respecto del ordenamiento jurídico español y se abriría, según el CATN, un proceso constituyente, con el objetivo fundamental de dotar al nuevo Estado ya creado de una Constitución. Como ya señalamos al principio, se parte en este trabajo de un concepto de poder constituyente ontológico, que incluye tanto el periodo de destrucción de las normas jurídicas que vinculan a Cataluña con España, como el momento político que sirve para dotar a un pueblo de una Constitución que institucionalice el nuevo Estado. Al margen de esta cuestión, el CATN entiende que todo el proceso secesionista debe llevarse a cabo sin vacío jurídico, por lo que a la vez que se proclama el Estado catalán en el Parlamento, o inmediatamente después, se debería de establecer un régimen transitorio de normas a través de una ley sobre el proceso constituyente, que podría tomar la forma de «Constitución provisional» (p. 20). Dicha norma, inimpugnable porque proviene de un órgano soberano, no tendría que ser aprobada por una

12 El apartado sexto de la Resolución 1/XI del Parlamento de Cataluña, de 9 de noviembre, antes citada, «reitera que esta cámara y el proceso de desconexión democrática del Estado español no se supeditarán a las decisiones de las instituciones del Estado español, en particular del Tribunal Constitucional, que considera falto de legitimidad y de competencia a raíz de la sentencia de junio de 2010 sobre el Estatuto de autonomía de Cataluña, votado previamente por el pueblo en referéndum, entre otras sentencias». 
mayoría especialmente cualificada y tendría que reglar el procedimiento constituyente, adaptar el sistema institucional y regular provisionalmente determinadas materias. En realidad, este modelo de Constitución provisional es bastante similar a las adoptadas en algunos países del Este de Europa en su transición del comunismo a la democracia, en Sudáfrica tras el final del Apartheid o en la misma España tras la muerte de Franco, cuando se aprobó en referéndum la Ley para la Reforma Política en $1977^{13}$.

El cuanto al procedimiento constituyente en sí mismo, la Constitución provisional tendría que prever la realización de unas elecciones propiamente constituyentes, a quién le corresponde llevar la iniciativa constitucional tras esas elecciones, la forma en la que se tramitaría y aprobaría en el Parlamento la nueva Constitución, las fórmulas de participación ciudadana y la ratificación mediante referéndum de la nueva Norma Fundamental. En lo referido al sistema institucional, el CATN aconseja mantener el establecido en el actual Estatuto de Autonomía hasta que se lleve a cabo la Constitución catalana, aunque la norma provisional tendría que abordar las adaptaciones lógicas desde la perspectiva de los distintos poderes y órganos del nuevo Estado de Cataluña (por ejemplo, establecer una jefatura del Estado, un poder judicial y una serie de autoridades independientes).

La regulación provisional de algunas materias se tendría que hacer, según el CATN, desde la perspectiva de la mínima incidencia para no condicionar las decisiones del futuro poder constituyente catalán. En cuanto a los derechos y libertades, la Constitución provisional tendría varias opciones: bien crear un catálogo propio, bien remitirse mediante una norma puente a los derechos fundamentales previstos en la Constitución española y el Convenio Europeo de Derechos Humanos. Llama la atención esta solución, en la medida en que en una Cataluña recién independizada, no estarían operativos ni la Constitución española ni el Convenio citado, de aplicación a Cataluña mientras esta siga formando parte del Estado español. El mismo CATN reconoce esta limitación (p. 27), al señalar que la garantía de los derechos y libertades quedaría en este periodo provisional en manos de los jueces ordinarios y del Consejo de Garantías Estatutarias y su control sobre los proyectos y proposiciones de ley, que fue previsto en la reforma del Estatuto de 2006 y anulado por el TC en la sentencia 31/2010. En lo referente al régimen provisional de la nacionalidad, el órgano asesor propone seguir los

13 El propio CATN señala en la p. 21, que «Se podrían tener en cuenta igualmente algunos de los elementos que configuraron el proceso constituyente español de los años 1977 hasta 1978». Sobre las normas provisionales en periodos constituyentes, existe abundante literatura española y comparada; al respecto, ver Requejo PAGÉs, J.L.: Las normas preconstitucionales y el mito del poder constituyente, Centro de Estudios Políticos y Constitucionales, Madrid, 1998; Vergottini, G. de: «Costituzionalismo europeo e transizioni democratiche», en Calamo Specchia, M., Carli, M., Di Plinio, G. y Toniatti, R. (a cura di): I Balcani occidentali. Le costituzioni della transizione, Giappicheli, Turín, 2008 y PAlermo, F.: «Comparative Law and the «Proceduralization» of Constitution - Building Processes», en RAue, J. y SuTter, P. (Eds): Facets and Practices of State - Building, Martinus Nijhoff Publishers, Leiden - Boston, 2009. 
principios de la Convención Europea de la Nacionalidad de 1997, y aplicar el criterio sobre la ciudadanía catalana que prevé la regla del artículo 7 del Estatuto de Autonomía, por la que son ciudadanos catalanes los nacionales españoles con vecindad administrativa en un municipio de Cataluña. Durante el periodo transitorio, hasta que las reglas definitivas fueran establecidas por la Constitución, se podrían establecer normas para ampliar el ámbito subjetivo de la nacionalidad catalana y un mecanismo específico para aquellas personas que residiendo en Cataluña quisieran renunciar a la misma, lo que supondría su exclusión del derecho de sufragio (p. 32).

En último lugar, el CATN aborda la cuestión del régimen lingüístico dentro del periodo de transición hacia la Constitución catalana. La Generalidad debería tomar medidas, ya desde el comienzo, para «garantizar el catalán como lengua de uso general y ordinario en Catalunya y mantener el reconocimiento y el derecho de uso del castellano» (p. 33). En el ámbito de las administraciones, el régimen no debería ser distinto del que funciona en la actualidad, que obliga al conocimiento del catalán para acceder a la mayor parte de la función pública que se realiza en Cataluña. Sin embargo, en lo que respecta a la relación de la propia administración con los ciudadanos, el órgano consultivo se muestra favorable hacia la preferencia del uso del catalán sobre el castellano, recuperando así la regla incorporada por la reforma del Estatuto de 2006, que después fue dejada sin efecto por el TC también en la sentencia 31/2010. En el contexto del poder judicial, el CATN llama a las instituciones provisionales a completar las lagunas que en materia lingüística ha dejado sin colmar, hasta el momento, la Ley Orgánica del Poder Judicial, asegurando el conocimiento adecuado y suficiente del catalán para el acceso a las plazas de juez, fiscal, secretario y personal de la Administración de justicia (p. 34).

\section{La sucesión de ordenamientos y Administraciones}

Hasta el momento en el que sea un Estado completamente independiente e incluso con posterioridad, en Cataluña deberá existir un ordenamiento jurídico pleno y una administración completa que se encargue transitoriamente de proveer de servicios a los ciudadanos, así lo exige la seguridad jurídica, uno de los principios esenciales del Estado de Derecho. Para abordar esta situación, el CATN ha elaborado el informe n. ${ }^{\circ} 16$, titulado «La sucesión de ordenamientos y Administraciones», publicado el 28 de julio de 2014, que pasamos a analizar brevemente, dejando al margen la cuestión de la continuidad de los contratos entre particulares y entre estos y la administración pública.

En lo referido a la plenitud del ordenamiento jurídico, el CATN señala que dentro de la Constitución provisional, en una norma ad hoc realizada por el Parlamento catalán o a través de un decreto-ley del Gobierno de la Generalidad, se tendrá que decidir la continuidad de los sectores materiales que hoy en día operan 
en Cataluña (derecho penal, mercantil, laboral, ordenación general de la economía y crédito y diversos aspectos del derecho civil y administrativo). Este derecho material, tiene, como se puede imaginar, un doble origen: el propiamente autonómico, derivado de las competencias que ostenta la Generalidad gracias a la Constitución y el Estatuto, y el Estatal, que se aplica en Cataluña de forma directa o supletoria. Esta no sería una cuestión excesivamente difícil de abordar según el órgano consultivo, en la medida en que en Cataluña ya se han vivido situaciones parecidas, aunque obviamente no tan complejas, como es el caso de la abolición de los fueros por Felipe V, el advenimiento de la República y posterior instauración de la dictadura en 1931 y 1939 y, por supuesto, la construcción del Estado social y democrático de Derecho después de la Constitución de 1978 (pp. 9 y 10). El CATN considera un buen punto de partida el artículo 34 de la Constitución provisional escocesa, hecha pública en junio de 2014 por si finalmente la secesión hubiera llegado a buen puerto ${ }^{14}$.

Otros dos aspectos importantes sobre el tema: lo dicho para el derecho material, vale también para el procesal, motivo por el cual deberán quedar vigentes en Cataluña, hasta que se aprueban otras normas que las sustituyan por el Parlamento del ya Estado independiente, la Ley de Enjuiciamiento Civil, la Ley de Enjuiciamiento Criminal, la Ley de Procedimiento Administrativo, la Ley General Tributaria, la Ley Reguladora de la Jurisdicción Contencioso Administrativa y el Estatuto de los Trabajadores. Además, en la Constitución provisional o ley específica sobre la continuidad de ordenamientos, se tendrá que especificar qué órganos de la Cataluña transitoria se ocuparán de las potestades que actualmente ejercen por ejemplo el Tribunal Constitucional, las administraciones independientes, el Consejo General del Poder Judicial o el Tribunal Supremo entre otros (p. 19). Es posible que dentro de los órganos provisionales, existan funcionarios que, «puedan llevar a cabo una opción personal de abandonar Cataluña, pero hay que asumir que esta circunstancia encontrará mecanismos de suplencia y que la mayoría continuarán ejerciendo sus funciones» (p. 20). Se prima por tanto la funcionalidad de la estatalidad, por encima de los derechos fundamentales de los ciudadanos.

En cuanto al derecho convencional y supranacional, resulta evidente que la mayor parte del mismo dejará de ser operativo porque es eficaz en Cataluña en la medida en que forma parte del Estado español, que es quien ha firmado y ratificado los Tratados internacionales. No obstante, el CATN señala que en lo referido al derecho internacional que garantiza derechos y libertades a los ciudadanos,

14 El CATN da un contenido concreto a la disposición sobre la continuidad de ordenamientos jurídicos: «Las normas jurídicas estatales y autonómicas, vigentes en Catalunya el día anterior a la proclamación de la independencia, continuarán vigentes y aplicables hasta su modificación o derogación por normas aprobadas por los órganos del nuevo Estado en todo aquello que no se opongan a las disposiciones de la presente ley constitucional provisional. Las referencias que se hacen a las autoridades u órganos del Estado español se tienen que entender hechas a las autoridades u órganos catalanes homólogos».

UNED. Teoría y Realidad Constitucional, núm. 37, 2016, pp. 499-527 
el Parlamento de Cataluña podría hacer un acto unilateral de recepción o de remisión para que los poderes públicos y tribunales lo siguieran teniendo en cuenta a la hora de tomar sus decisiones. En lo que respecta al derecho comunitario, el órgano asesor reconoce que solo estará vigente el derecho derivado que haya sido traspuesto por el Estado español o por la Comunidad Autónoma, mientras que «el derecho comunitario de aplicación directa mediante reglamentos y de otra normativa del acquis comunitario, en principio no puede continuar vigente de acuerdo con el mismo criterio aplicable a los tratados internacionales y el derecho supraestatal de las organizaciones internacionales» (p. 24).

En cuanto a la sucesión de administraciones, aquí de nuevo el CATN distingue entre dos posibilidades. La primera hace referencia a la (deseable) actitud colaborativa del Estado español, lo que permitiría la creación de una comisión paritaria para abordar todas las cuestiones materiales y de personal que implicaría la asunción por parte de la Cataluña independiente, del conjunto de administraciones públicas que al día de hoy son ejercidas competencialmente por el Estado. La segunda dibuja un posible escenario de no colaboración por parte de España, lo que implicaría el recurso a la mediación internacional para solventar la cuestión de la sucesión de administraciones. En caso de una secesión no pactada, las negociaciones entre el Estado español y el Estado catalán independiente deberían llevarse a cabo en el marco internacional y los acuerdos en que desembocaran tendrían el carácter de tratado internacional, lo que daría a Cataluña una mayor capacidad de negociación, pero tendría el inconveniente de que las negociaciones se realizarían con posterioridad a que la secesión se hiciera efectiva (p. 32). Obviamente, este razonamiento no explica por qué el Estado español tendría que negociar en el plano internacional, lo que se ha negado a negociar en el plano bilateral.

Una última cuestión relevante a tratar en el informe n. ${ }^{\circ} 16$ es qué ocurrirá con las personas al servicio de la Administración General del Estado, que según el CATN pueden generar «una problemática especial» (p. 42) debido a que tienen atribuidas funciones de especial relevancia social, a menudo conectadas con la seguridad del tráfico jurídico y la legalidad. Hablamos del personal judicial, los notarios y registradores, los funcionarios locales con habilitación nacional, los inspectores de trabajo y seguridad social y los profesores e investigadores universitarios (expresamente citados en el informe). El CATN considera que en un escenario de colaboración, sus derechos adquiridos y escala promocional pueden ser respetados siempre que se cumplan los requisitos sobre el perfil lingüístico y se prevea un régimen transitorio de igualación para no generar agravios con el resto de los funcionarios del futuro Estado catalán. Para aquellos que ejercen «poder público» (jueces y magistrados), será además indispensable obtener la nacionalidad catalana (p. 45). Sin embargo, en un escenario de no colaboración del Estado español, al estar sometidos al principio de jerarquía administrativa, difícilmente estos funcionarios podrán incorporarse al nuevo Estado catalán, lo que obligaría al reclutamiento de nuevo personal «eventualmente poco experto» o «a la forma- 
lización de una oferta lo bastante ventajosa a las personas al servicio de la Administración española para facilitar su abandono y estimular el ingreso en la Administración catalana» (p. 46) $)^{15}$.

\section{Repartir los bienes y las deudas compartidas: la distribución de activos y pasivos}

La secesión supone asimilar al Estado a una especie de sociedad anónima por acciones: sus bienes muebles e inmuebles se pueden repartir entre los distintos sujetos que lo componen, más allá del concepto de proindiviso que emerge como consecuencia de la aplicación del principio de soberanía popular. Para analizar los diversos aspectos de la sucesión de Estados, en materia de bienes y deudas, establecer la cuantificación numérica de esos bienes y deudas e identificar los criterios aplicables a la hora de determinar los derechos y obligaciones de las partes sobre la cuestión, el CATN ha elaborado el informe n. ${ }^{\circ} 7$, titulado «La distribución de activos y pasivos», presentado el 14 de julio de 2014. Pasamos a analizarlo a continuación.

El órgano asesor parte de la idea de que el reparto de bienes y deudas entre España y Cataluña se realizará al margen del ordenamiento jurídico español, por lo que privilegia las normas de derecho internacional. Normas, por otro lado, que no se encuentran en vigor, como es el caso de la Convención de Viena de 1983, pero que pueden servir de marco operativo si el Estado matriz y el Estado sucesor acuerdan que regulen el reparto de bienes y deudas después de que se produzca la secesión. Además, convendría tener en cuenta otras «fuentes auxiliares» como la resolución Guiding principles relating the succesions of States in respect to property and debt adoptada en 2001 por el Institut de Droit International en su sesión de Vancouver. La importancia de este documento radicaría en el hecho de que recoge la práctica internacional de los años noventa, derivada de los diferentes casos de sucesión de Estados que tuvieron lugar en Europa central y oriental. Por último, el acuerdo entre España y Cataluña sobre la cuestión, tendría que adoptar la forma de tratado internacional, lo que implicaría responsabilidad en caso de incumplimiento de alguno de sus extremos.

La doctrina que sigue en la cuestión de reparto de bienes y deudas el CATN, es la de la sucesión universal. Ve improbable la doctrina de la «tabla rasa» o clean state, en la medida en que ésta fue pensada esencialmente para los procesos de descolonización. La Convención de Viena antes citada, establece un periodo de seis meses para que las partes implicadas establezcan contactos y negociaciones

15 La oferta pasaría por incluir el derecho a obtener la nacionalidad catalana en caso de que la persona afectada no dispusiera de las condiciones exigidas para acceder, de acuerdo a lo establecido en la Convención Europea sobre la Nacionalidad de 1997. 
directas: pasado ese plazo, Cataluña podría recurrir a la mediación internacional o iniciar un mecanismo jurisdiccional de solución pacífica de controversias como el arbitraje ante la Corte Internacional de Justicia, sobre aquellos ámbitos en los que no se haya llegado a un acuerdo (p. 14). En situación de normalidad, las negociaciones se realizarían a varias bandas entre el Estado predecesor, el Estado sucesor, las autoridades monetarias internacionales (FMI, Banco Mundial), la UE, por ejemplo, a través del Banco Central Europeo, así como ciertos organismos que representan los intereses de los acreedores, que se agrupan en los llamados Club de París y Club de Londres, respondiendo a la naturaleza pública o privada de los créditos.

Los principios jurídicos que presidirían las negociaciones entre España y Cataluña serían la proporcionalidad, la territorialidad, la equidad, la trasparencia, la buena fe y, por supuesto, la voluntad de las partes. A partir de estos principios, el CATN establece cómo debería de quedar repartida la deuda del Estado español y el reparto de bienes una vez sea efectiva la secesión.

En cuanto a la primera cuestión, en principio, Cataluña solo podría hacerse cargo, íntegramente, de la deuda propia de la Generalidad, Diputaciones, Consejos Comarcales y ayuntamientos catalanes. Dentro de lo que sería la deuda territorializable, el Estado catalán tendría que hacerse cargo, proporcionalmente, de la deuda contraída por el Estado español para hacer obras, servicios o inversiones en la todavía Comunidad Autónoma, teniendo en cuenta el déficit histórico de inversiones en la región y que mientras formaba parte del Estado predecesor, Cataluña ya contribuía a su financiación. Además, el CATN considera que el Estado sucesor debería hacerse cargo de parte de la deuda contraída para obras pendientes de ejecución o a medio ejecutar, siendo la excepción el principio de transmisión de bienes sin contraprestación. La deuda no territorializable, es decir, aquella deuda contraída para dar servicios comunes a todos los ciudadanos españoles, será repartida de forma proporcional entre España y Cataluña, siendo el criterio demográfico el que debe de primar a la hora de establecer los cálculos para llegar a un acuerdo con respecto a las cifras (p. 21). El pago de este tipo de deuda, quedará condicionado a que España haga transferencia de los bienes que han sido adquiridos en los distintos departamentos ministeriales, como podría ser el caso del material vinculado a la defensa del Estado.

Aunque ninguna norma de derecho internacional regula con precisión la transmisión de deudas del Estado predecesor con organizaciones internacionales, en principio no cabría la posibilidad de transmitir esa deuda al Estado catalán, al menos hasta que éste sea considerado parte de la organización como miembro de derecho pleno (p. 23). Aquí, según el CATN, se tendría que distinguir entre admisiones directas y aquellas organizaciones en donde Cataluña tendría que superar el proceso de admisión como nuevo Estado, ámbito donde la renuncia a pagar la deuda contraída por el Estado predecesor podría funcionar, a nuestro parecer, como mecanismo de presión para que España y sus gobiernos no pusieran 
trabas para la incorporación del Estado catalán a la sociedad internacional con plena normalidad.

Algo parecido ocurre con la deuda entre el Gobierno central y la Generalidad, que a fecha de 14 de julio del 2014, el CATN cifra en 9375 millones de $€$. Según el órgano asesor, «En el escenario de que el Estado español no cumpla sus compromisos financieros y de inversiones con Catalunya, especialmente una vez iniciado el proceso de secesión, bien sea como medida de compulsión económica, bien sea como resultado de su situación económica, el Estado catalán podría estar legitimado para exigir la reducción de la deuda del Estado español que tenga que asumir como consecuencia de la sucesión de Estados en una cantidad equivalente» (p. 24). Además, Cataluña podría exigir, de acuerdo a la sentencia del Tribunal de Arbitraje de la Sociedad de Naciones sobre la indemnización reclamada por Rusia al Imperio Otomano, compensaciones económicas por incumplimiento de los compromisos financieros y de inversiones (p. 25).

Pasemos ahora al reparto de bienes. En cuanto a los bienes territorializables, según el CATN, todos los bienes públicos situados en el territorio secesionado pasarían al Estado sucesor de forma directa y sin contraprestación, tal y como señala la Convención de Viena de 1983 (ello incluiría edificios, servicios, corporaciones públicas y arsenal militar). Los no territorializables, como las reservas en el Banco de España, cuentas corrientes o títulos de empresas públicas y privadas, deberían transmitirse al Estado catalán en la misma proporción que se determine para la transmisión de la deuda pública no territorializable, tal y como establece el principio de equidad. Con respecto a los bienes muebles, aquellos que pertenezcan a la Administración General del Estado y no estén sitos en Cataluña, darán lugar a una compensación proporcional a Cataluña, mientras que para aquellos que estén sujetos a movilidad (trenes, aviones del Estado, vehículos), el CATN recomienda seguir el ejemplo de Eslovaquia y Eslovenia, que tuvieron que establecer un control físico sobre los mismos a fin de asegurarse que se encontraban en el «territorio nacional» en el momento efectivo de la independencia (p. 27).

\section{LA INTEGRACIÓN DE CATALUÑA EN LA UNIÓN EUROPEA Y EN LA SOCIEDAD INTERNACIONAL}

Una vez Cataluña sea un Estado soberano, el CATN se plantea qué ocurriría con respecto a su pertenencia a la UE y su integración en las demás organizaciones internacionales. Para ello, elaboró sendos informes, el n. ${ }^{\circ} 6$, titulado «Las vías de integración de Cataluña en la Unión Europea», publicado el 14 de abril de 2014, y el n. ${ }^{\circ} 13$, publicado el 28 de julio de 2014, y titulado «La integración en la comunidad internacional». Comenzaremos con la cuestión relativa a la conversión de Cataluña en un Estado miembro de la UE.

Con respecto a este tema, la postura del CATN es optimista, cuando no meramente voluntarista. Como señala en la p. 39 del informe n. ${ }^{\circ}$, que será el que 
a partir de ahora citemos, «El dilema, en realidad, no es pues si Catalunya acabará formando parte de la UE, sino cuándo y cómo lo hará». Como ya se vio en la cuestión escocesa, el posible abandono del proyecto de integración comunitario, de una región independizada de un Estado miembro, es un tema que puede condicionar el apoyo y la legitimidad de los procesos secesionistas. Así las cosas, el órgano consultivo hilvana las siguientes razones jurídicas y políticas, para apoyar la tesis de que la conversión de Cataluña en un Estado soberano, apenas variará su estatuto constitucional dentro de la UE.

Según el CATN, no existe regulación expresa en la UE para abordar el caso de que un territorio de un Estado miembro abandone la disciplina de los Tratados comunitarios como consecuencia de la secesión. Tampoco en el derecho internacional (pp. 8-13). El marco de referencia principal en este último ámbito sería la Convención de Viena de 1978, que prevé como regla general, especialmente con relación a los tratados multilaterales, la continuidad de los derechos y de las obligaciones convencionales en caso de sucesión de Estados. Ocurre, como reconoce el propio CATN, que esta regla general se aplica según el artículo 4 de la Convención, «sin perjuicio de las normas relativas a la adquisición de la calidad de miembro y sin perjuicio de cualquier otra norma pertinente de la organización», como es el caso de la UE y su ya conocido artículo 49 TUE. No obstante, «el carácter inédito del caso catalán incrementará la amplitud del margen de libertad de la UE suele darse a la hora de seleccionar, interpretar y aplicar el Derecho europeo» (p. 13). Según el CATN, la UE es una organización pragmática, que antepone el valor de los intereses políticos a la eficacia del derecho comunitario, como demuestra el caso de Groenlandia y la unificación alemana ${ }^{16}$.

El órgano consultivo considera asimismo que Cataluña cumplirá holgadamente con los valores comunitarios y las exigencias de los criterios de adhesión establecidos por el Consejo Europeo de Copenhague el 21 y 22 de junio de 1993. Además, para ingresar en la UE, no es condición sine qua non que el futuro Estado catalán haya sido previamente reconocido formalmente como Estado o como sujeto internacional por algún otro Estado o por determinadas organizaciones internacionales (p. 19). A partir de esta suposición, pues el CATN no cita ningún supuesto en el que en la UE se hayan incorporado Estados a la condición de miembros, a través de reconocimientos de soberanía implícitos o informales, se abordan las reglas procedimentales y las consecuencias prácticas de los diferentes escenarios que se pueden producir. El CATN ve como escenario más plausible (es al que dedica más páginas) el de la ampliación interna, concepto elaborado para la ocasión y que ha hecho indudable fortuna en la opinión pública y los medios académicos catalanes ${ }^{17}$.

16 La compatibilidad de estos casos con la hipotética situación catalana o escocesa, ha sido contradicha por Mangas Martín, A.: «La secesión de territorios en un Estado miembro: efectos en el derecho de la Unión Europea», Revista de Derecho de la Unión Europea, n. ${ }^{\circ} 25,2013$.

17 Matas i Dalmases, J., González Bondia, A., Jaria i Manzano, J. y Román i Martín, L.: L'ampliació interna de la Unió Europea. Anàlisi de les consequiències juridicopolítiques per a la Unió Europea en cas de 
La ampliación interna es un procedimiento ad hoc en el que las normas jurídicas de los Tratados se aplicarían de forma flexible para que Cataluña u otra región que forme parte de la UE, continúe en el proyecto comunitario sin tener que aplicar el artículo 49 TUE después de independizarse de un Estado miembro. El Presidente de la Generalidad enviaría una solicitud al Consejo Europeo, y éste por unanimidad aceptaría, como ya hizo en el caso alemán, la continuidad de Cataluña en la UE como Estado miembro. El propio órgano intergubernamental, establecería el estatuto transitorio hasta que Cataluña realice todas las adaptaciones necesarias en el orden interno para cumplir con las exigencias del derecho comunitario primario y secundario. Lógicamente, la entrada de un nuevo Estado requeriría algunas modificaciones en los Tratados, para lo cual habría que utilizar el mecanismo de reforma del artículo 48 TUE, «ya que, en rigor, el procedimiento del artículo 49 TUE está previsto para la modificación del derecho originario en el marco del procedimiento de adhesión de nuevos Estados que no han formado parte de la Unión Europea» (p. 22) ${ }^{18}$.

Si la ampliación interna no puede llevarse a cabo, el CATN establece otras dos vías procedimentales para que de forma subsidiaria Cataluña termine formando parte de la UE. La primera sería utilizar el procedimiento de adhesión del artículo 49 TUE, pero modulado con la adopción de medidas simplificadoras y transitorias específicas, con el objetivo de que se continúe aplicando al territorio catalán y a sus ciudadanos, la mayor parte del derecho comunitario. La segunda vía sería una adhesión ordinaria, también del artículo 49 TUE, pero esta vez sin mecanismos de flexibilización, lo que implicaría que Cataluña tendría la misma condición de aspirante, que cualquier otro Estado que no haya formado anteriormente parte de la UE, como es el caso de Turquía, Macedonia, Montenegro o Serbia. Por último, el CATN prevé la improbable posibilidad de que Cataluña quedara excluida de la UE ante la negativa de la UE a iniciar negociaciones o como consecuencia del bloqueo de algún Estado miembro. Según el órgano asesor, esto no sería posible, porque implicaría que se estaría aplicando el artículo 50 TUE, que hace referencia a la retirada de Estados miembros del UE, a una región que quiere seguir formando parte del proyecto comunitario (p. 30).

Todas estas vías, todos estos escenarios, se producirían en un sentido o en otro dependiendo de la actitud que tomen las instituciones comunitarias y los

secessió o de dissolució d'un estat membre, Fundació Josep Irla, Barcelona, 2010 y Palomares Amat, M.: «Las decisiones de los Jefes de Estado y de Gobierno, en el seno del Consejo Europeo, como categoría jurídica para regular, transitoriamente, la participación en la Unión Europea de nuevos Estados surgidos de la separación de Estados miembros», Revista d'Estudis autonòmics i federals, n. ${ }^{\circ}$ 17, 2013, pp. 146-183. Para el caso escocés han propuesto soluciones similares, con algunas variantes, Thorp, A. y Thompson, G.: Scotland, Independence and the EU, House of Commons, UK, 2011, p. 7 (www.parliament-uk).

18 Existen visiones distintas a este argumento del CATN; ver al respecto, Mangas Martín, A.: «Cataluña: ¿no habrá independencia?», El Cronista del Estado Social y Democrático de Derecho, n. ${ }^{\circ} 42,2014$ y Miguel BÁRCEnA, J. de: «La cuestión de la secesión en la Unión Europea: una visión constitucional», Revista de Estudios Políticos, n. ${ }^{\circ} 165,2014$, pp. 211-245. 
Estados miembros, que obviamente tienen sus propios intereses. El CATN cree que es necesario tener en cuenta cuestiones como la capacidad de la UE para absorber más Estados, el miedo a que se produzcan tensiones territoriales en otros países o la ilegalidad de una secesión regional desde la perspectiva del ordenamiento comunitario. Sin embargo, es de la opinión de que no permitir la entrada de Cataluña a la UE, o poner trabas a su incorporación, supone ir en contra de los valores que representa el proceso de integración, una irracionalidad jurídica y política (p. 34) porque la región ya forma parte de la propia Unión y con ello se excluiría a siete millones de personas de la ciudadanía europea y un error estratégico en la medida en que la UE no puede perderse las oportunidades que ofrece Cataluña para el mercado supranacional. En el caso en el que la adhesión no pudiera llevarse a cabo, el CATN señala como alternativas la posibilidad de que Cataluña lleve a cabo acuerdos bilaterales con la UE, se integre en la Asociación Europea de Libre Comercio (EFTA) o realice acuerdos de libre comercio o uniones aduaneras con terceros Estados.

Como ya hemos señalado más arriba, el tema de la incorporación de Cataluña a la sociedad internacional se trata en el informe n. ${ }^{\circ} 13$, publicado el 28 de julio de 2014, y titulado «La integración en la comunidad internacional». Para que esto ocurra, el Estado catalán debería en primer lugar ser reconocido por otros Estados, algo que puede ocurrir de manera explícita, con un acto formal y jurídico, de manera tácita, estableciendo relaciones diplomáticas o votando favorablemente el ingreso de un Estado determinado en una organización intergubernamental (p. 13). Sin embargo, para que la fase de reconocimiento sea efectiva, el CATN recuerda que en Cataluña debe en primer lugar existir un Estado, que como se sabe, desde una perspectiva sociológica hace referencia a una población, «mayoritariamente de acuerdo con la nueva situación», que vive en un territorio y que está sometido a un Gobierno y a unas instituciones. El reconocimiento progresivo de otros sujetos tiene que ser consecuencia de una estrategia multilateral donde la Generalidad vaya buscando, antes de que se proclame la independencia, el apoyo del máximo número de Estados posibles.

Con respecto a la sucesión de tratados internacionales, el CATN reconoce que la práctica existente «es diversa e incluso contradictoria» (p. 18). Más allá de la Convención de Viena de 1978 sobre sucesión de Estados, los casos concretos mostrarían que las soluciones no responden a consideraciones jurídicas, sino sobre todo a consideraciones pragmáticas y de oportunidad. Sin embargo, según el órgano consultivo, pueden identificarse unos principios genéricos, que pueden resumirse de la siguiente forma: la sucesión debe conducir a un resultado equitativo, partiendo de la libertad de los Estados interesados para fijar a través del acuerdo este resultado. Además, todas las partes que participan en la sucesión deben respetar las normas imperativas de derecho internacional general, y en particular, las relativas al respeto de los derechos fundamentales de la persona y los derechos de los pueblos y las minorías. Como no podía ser de otra manera, esta tesis es perfectamente defendible, ocurre que muchas de las normas citadas, como 
la Convención de Viena sobre sucesión de Estados (1978) y la Convención de Viena sobre sucesión de Estados en materia de bienes, archivos y deudas (1983), o bien no están en vigor, o bien han sido ratificadas por un número escaso de Estados, entre los que por cierto no se encuentra España.

En cuanto a la pertenencia a las organizaciones internacionales de carácter intergubernamental, el CATN distingue entre aquellas que tienen un procedimiento formal de adhesión, y aquellas en las que para convertirse en miembro de pleno derecho solo es necesario un acto unilateral del Estado catalán, como sería el caso de la Organización Internacional para la Propiedad Intelectual o la Unión Internacional de Telecomunicaciones. El órgano consultivo va desgranando, a partir de esta constatación, los requisitos y procedimientos necesarios para pertenecer a las Naciones Unidas y sus organismos especializados, las instituciones financieras internacionales, los organismos regionales paneuropeos (Consejo de Europa), la Corte Penal Internacional, la Organización Mundial del Comercio o la Organización para la Cooperación y el Desarrollo Económico. En todos los casos se hace un minucioso análisis del mecanismo formal de adhesión y se realizan algunas recomendaciones para que la incorporación de Cataluña sea un éxito, si bien la ponderación entre las dificultades políticas y jurídicas y las posibilidades de encontrar fórmulas para que el nuevo Estado catalán permanezca en las organizaciones internacionales una vez independizado, adquiere unos matices y una objetividad que a nuestro modo de ver no están presentes en el asunto de la integración de la hoy región en la UE.

\section{CONCLUSIONES}

El presente trabajo ha pretendido realizar una síntesis de los aspectos fundamentales de algunos de los informes llevados a cabo por el Consejo Asesor para la Transición Nacional, órgano nombrado por la Generalidad de Cataluña para establecer las líneas maestras de la conversión de la actual Comunidad Autónoma en un Estado soberano. Como marco metodológico hemos utilizado una aproximación ontológica del concepto de poder constituyente, lo que abarca tanto el conjunto de actos necesarios para que Cataluña se desconecte del Estado español (pars destruens), como el conjunto de decisiones posibles para crear el Estado catalán y llevar a cabo su institucionalización a través de la correspondiente Constitución (pars construens). Como ya dijimos al principio, nos hemos centrado en aquellos informes que están relacionados con el derecho público, no con otros aspectos ajenos o tangenciales al mismo.

Hemos tratado de evitar un enfoque crítico, pues los argumentos utilizados por el CATN han sido o seguramente serán objeto de análisis en otros estudios que traten de manera pormenorizada aspectos como la viabilidad constitucional de la consulta, la dimensión comparada de los procesos de secesión, la integración de Cataluña en la Unión Europea o la naturaleza y extensión del derecho de auto- 
determinación como remedio en el derecho internacional. No obstante, en las conclusiones, creemos que es posible llevar a cabo una serie de objeciones globales, que no tienen que ver tanto con el contenido, producto sin duda de la libertad de expresión y la libertad de cátedra de los componentes del CATN, como con aspectos epistemológicos y estructurales, cuyo mejor tratamiento habría convertido a los informes en un instrumento más valioso para la institución que los demandó y para la comunidad científica que quiera acercarse a los diversos problemas que se abordan en los mismos. Las objeciones serían de tres tipos.

El primer problema viene derivado del propio Decreto 113/2013 que crea el CATN. En el mismo, el Gobierno de la Generalidad pide opinión sobre los pasos que se tienen que dar para completar la transición nacional de Cataluña hacia un Estado independiente. Es decir, el mandato opera como si existiera de facto una mayoría de ciudadanos que en la Comunidad Autónoma es favorable a la secesión, motivo por el cual, en el conjunto de los informes no hay sitio para otro tipo de expresiones institucionales que pudieran resolver mediante otras técnicas de integración, la crisis de la Constitución territorial española. Particularmente, como el contenido de los informes va mucho más allá del procedimiento democrático para encauzar el derecho de autodeterminación, la presencia de las posibles minorías, que en procesos de este tipo adquieren la naturaleza de nacionales, tendrían que haber sido objeto de una mayor atención desde el punto de vista de la afirmación de sus intereses y la protección de sus derechos, cuestión ampliamente tratada en el derecho comparado y en los organismos internacionales, como consecuencia de las distintas experiencias separatistas que ha habido en Europa y en el mundo en las últimas décadas.

Un segundo nivel de problemas aparece en el contexto metodológico. El conjunto de los informes, pero particularmente el n. ${ }^{\circ} 1 \mathrm{y} e l \mathrm{n} .{ }^{\circ} 10$, relativos a la consulta y el proceso constituyente en Cataluña, parte de la hipótesis de que dentro de las democracias constitucionales estables, integradas en marcos institucionales supranacionales, como es el caso de la española, es posible hacer una distinción clara entre la legitimidad y la legalidad. Para el CATN, la existencia de una hipotética mayoría electoral favorable a la secesión de Cataluña, es aval suficiente como para otorgar legitimidad a los poderes públicos catalanes en su objetivo de lograr un Estado soberano, lo que le conduce a teorizar sobre las distintas formas e instrumentos que la Generalidad tendría en su mano para desconectar del ordenamiento constitucional español. Resulta evidente que cuando se reflexiona en un plano constituyente, las razones jurídicas y positivas se diluyen y dan paso a un pensamiento creativo que, en el caso del CATN, le conduce a plasmar argumentos con un apoyo doctrinal meramente circunstancial (pensemos en la posible integración de Cataluña en la UE mediante la ampliación interna) o a trivializar acontecimientos gravísimos no tanto para quien los propicia, como para el conjunto de la sociedad que los debe soportar (por ejemplo la realización de una declaración unilateral de independencia o la proclamación del Estado catalán). 
El último nivel de objeciones, tiene que ver con el marco lingüístico y estratégico utilizado en el conjunto de los informes. Particularmente, el CATN se refiere siempre al Estado español como un sujeto hostil de las ansias de autogobierno del pueblo catalán, lo que en cierta forma contrasta con la lealtad y la actitud colaborativa que se le presuponen cuando de negociar una secesión por la vía de hechos se trata. El objetivo de esta caracterización, como queda claro en el informe n. ${ }^{\circ} 1$, es hacer recaer en el Estado la responsabilidad de las decisiones que en última instancia pueda tomar la Generalidad, como consecuencia de su oposición política al proceso independentista (p. 51). Sin embargo, es preciso recordar que el Estado español está constitucionalizado, la formación de su voluntad se hace a través de distintos órganos y las decisiones son consecuencia de la expresión del pluralismo político que ejercen los partidos y los ciudadanos. La inevitabilidad de la secesión por la vía de los hechos, que aparece en el conjunto de los informes del CATN como consecuencia de una caracterización histórica determinada del Estado español, encuentra como límite el hecho de que las mayorías que componen las Cortes Generales y otorgan la confianza al Gobierno, están sometidas al principio democrático y a la contingencia, como no podía ser de otra manera en un Estado constitucional.

TITLE: Manual to building a state (the reports of the Advisory Council for the National Transition of Catalonia)

ABSTRACT: The aim of this paper is to analyze the reports of the Advisory Council for the National Transition of Catalonia. The Advisory Council for the National Transition is a body created by the Government of Catalonia in 2013, to advise regional institutions in legal, political and economic issues related to the creation of an independent state. Methodologically, we used an ontological concept of constituent power, focusing on those aspects that in the reports studying the different dimensions of the democratic legitimacy of secession, the unilateral declaration of independence, the formation and building of the future Catalan state and, from an institutional point of view, the national and international consequences of self-determination.

Resumen: La pretensión de este trabajo es analizar los informes del Consejo Asesor para la Transición Nacional de Cataluña. El Consejo de Transición Nacional es un órgano creado por la Generalidad de Cataluña en 2013, para asesorar a las instituciones regionales en cuestiones jurídicas, políticas y económicas relacionadas con la creación de un Estado independiente. Metodológicamente, se ha utilizado un concepto ontológico de poder constituyente, priorizando aquellos aspectos que en los informes estudian las distintas dimensiones del proceso democrático para legitimar la secesión, la posible declaración unilateral de independencia, la formación y construcción del futuro Estado catalán y, desde una perspectiva institucional, las consecuencias nacionales e internacionales de la autodeterminación.

KEY wORDS: Advisory Council for the National Transition of Catalonia; constituent power; independent state; secession; national self - determination.

Palabras Clave: Consejo Asesor para la Transición Nacional de Cataluña; poder constituyente; Estado independiente; secesión; autodeterminación nacional.

FECHA DE RECEPCIÓN: 11.11.2015

FECHA DE ACEPTACIÓN: 18.01.2016

UNED. Teoría y Realidad Constitucional, núm. 37, 2016, pp. 499-527 